\title{
Severe tricuspid regurgitation after mitral valve surgery: the risk factors and results of the aggressive application of prophylactic tricuspid valve repair
}

\author{
Hiroshi Takano ${ }^{1,2} \cdot$ Miyoko Hiramatsu $^{1} \cdot$ Hirota Kida $^{1} \cdot$ Mitsuru Uenoyama $^{1}$. \\ Kei Horiguchi ${ }^{1} \cdot$ Takashi Yamauchi $^{1} \cdot$ Keiwa Kin $^{1} \cdot$ Yukitoshi Shirakawa $^{1}$. \\ Mitsunori Kaneko $^{3}$ - Takashi Daimon ${ }^{4}$
}

Received: 27 March 2016 / Accepted: 29 June 2016 / Published online: 8 August 2016

(C) The Author(s) 2016. This article is published with open access at Springerlink.com

\begin{abstract}
Purpose This study aimed to examine the risk factors for severe postoperative tricuspid regurgitation (TR) in patients undergoing mitral valve surgery. We also studied the effects of prophylactic tricuspid valve repair (TVR) on severe postoperative TR.

Methods We retrospectively studied 125 patients without severe TR who underwent mitral valve surgery from 1987 to 2006. Patients did not undergo TVR before 1998 (the early period, $n=54$ ). In 1998 (the late period, $n=71$ ), patients with a preoperative tricuspid annular diameter of $\geq 35 \mathrm{~mm}$ underwent TVR using an annuloplasty ring $(n=52)$.

Results In the analysis of the early period, the rates of freedom from severe TR at 10 and 20 years after surgery were 76 and $59 \%$, respectively. A multivariate analysis identified moderate preoperative TR as a significant risk factor for severe TR. In the late period, none of the 52 patients who underwent TVR developed severe TR. However, 4/19 patients who did not undergo TVR developed severe TR, and all of these four patients had a preoperative tricuspid annular diameter of $\leq 35 \mathrm{~mm}$.
\end{abstract}

Hiroshi Takano

htakano@dokkyomed.ac.jp

1 Department of Cardiovascular Surgery, Osaka General Medical Center, 3-1-56 Bandaihigashi, Sumiyoshiku, Osaka 558-8558, Japan

2 Department of Thoracic and Cardiovascular Surgery, Dokkyo Medical University Koshigaya Hospital, 2-1-50 Minamikoshigaya, Koshigaya 343-8555, Japan

3 Department of Cardiovascular Surgery, Suita Tokushukai Hospital, 21-1 Senriokanishi, Suita 565-0814, Japan

4 Department of Biostatistics, Hyogo College of Medicine, 1-1 Mukugawacho, Nishinomiya 663-8501, Japan
Conclusions Moderate preoperative TR is a significant risk factor for severe postoperative TR in patients undergoing mitral valve surgery. The aggressive application of TVR can prevent severe postoperative TR; however, tricuspid annular dilatation might not be a good indicator for TVR.

Keywords Mitral valve $\cdot$ Surgery $\cdot$ Tricuspid regurgitation · Tricuspid valve repair · Tricuspid annular dilatation

\section{Introduction}

Severe tricuspid regurgitation (TR) is associated with a reduction in exercise capacity and a poor functional outcome $[1,2]$. Patients with severe TR who undergo mitral valve surgery should undergo concomitant tricuspid valve repair (TVR) because TR does not usually resolve if only the mitral valve is repaired. However, it remains unclear whether patients with moderate or mild TR should undergo TVR at the time of mitral valve surgery. Some patients with moderate or mild preoperative TR develop severe late postoperative TR [3-9]. Thus, some authors recommend that such patients should undergo prophylactic TVR at the time of mitral valve surgery [3,6-10]. The recent guidelines for the management of valvular heart disease from the European Society of Cardiology/European Association for Cardio-thoracic Surgery [11] and the American College of Cardiology/American Heart Association [12] recommend that concomitant TVR should be considered in patients with tricuspid annular dilatation, prior evidence of right heart failure, or pulmonary hypertension (recommendation class IIa or IIb).

We have seen a considerable number of patients with insignificant preoperative TR who developed severe TR 
after mitral valve surgery. Since 1998, we have therefore performed TVR (tricuspid annuloplasty using a flexible prosthetic ring) more aggressively for patients with a dilated tricuspid annulus, regardless of the severity of TR. In this study, we retrospectively studied the risk factors for the development of severe TR in patients without severe preoperative TR dating back to the period before we began aggressively applying TVR. We also studied the effects of prophylactic TVR on severe postoperative TR. Finally, we assessed the validity of our indication (i.e., tricuspid annular dilatation) for TVR in patients without severe TR who underwent mitral valve surgery.

\section{Methods}

\section{Study population}

Between 1987 and 2006, 237 patients underwent mitral valve surgery at Osaka General Medical Center (Fig. 1). We excluded cases involving severe (grade $3+$ ) preoperative TR $(n=81)$, patients in whom the tricuspid annular diameter (TAD) was not measured $(n=9)$, patients who died within 1 year after surgery (including six hospital deaths) $(n=9)$, patients with the postoperative recurrence of significant mitral valve disease or periprosthetic valvular leakage $(n=7)$, patients who were lost to follow-up within 1 year $(n=4)$, and patients with organic (rheumatic) tricuspid valve disease $(n=2)$. The remaining 125 patients were included in this study. The study protocol was approved by the institutional ethics committee of Osaka General Medical Center (Approval number: 27-S1901).

In 1998, we changed our policy regarding TVR in patients undergoing mitral valve surgery. Before 1998 (early period), we only repaired the tricuspid valve in patients with severe TR. Beginning in 1998 (late period), we considered patients with a TAD of $\geq 35 \mathrm{~mm}$ as candidates for concomitant TVR, regardless of the presence or severity of TR. Thus, none of the 54 patients in the early period of this study underwent TVR, and 52 of the 71 (73\%) patients in the late period underwent TVR. Seven late-period patients were not treated according to the above-mentioned policy at the discretion of the surgeon; these included 6 of the 57 patients with a TAD of $\geq 35 \mathrm{~mm}$ who did not undergo TVR and one patient with a TAD of $<35 \mathrm{~mm}(28 \mathrm{~mm})$ who underwent TVR.

The characteristics of the 125 patients (early period, $n=54$; late period, $n=71$ ) are shown in Table 1 . Because there was a time difference between the early and late periods, the characteristics of the two groups, such as age, the rate of rheumatic disease, and the rate of atrial fibrillation or pulmonary hypertension (defined by a mean pulmonary

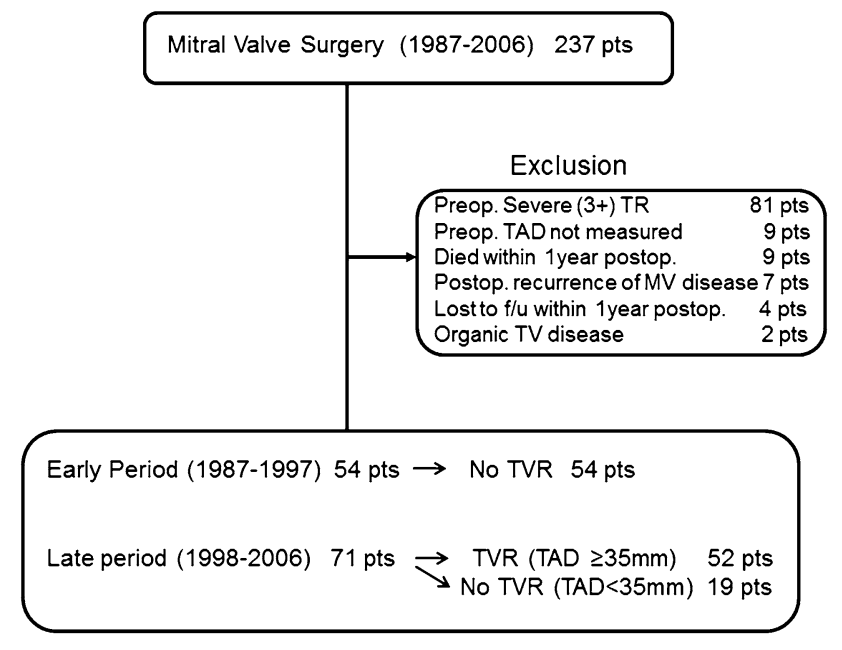

Fig. 1 A flow diagram of patients in the study. pts patients, $T R$ tricuspid regurgitation, TAD tricuspid annular diameter, $M V$ mitral valve, $f / u$ follow-up, $T V$ tricuspid valve, $T V R$ tricuspid valve repair

arterial pressure of $\geq 25 \mathrm{mmHg}$ on cardiac catheterization or preoperative echocardiography), were different from each other. The mitral valve was replaced in the majority of patients in this study, and this is conspicuous in the early period, where all but one underwent mitral valve replacement.

The severity of preoperative TR was classified as none (grade 0 ) in five patients, mild (grade $1+$ ) in 82 , and moderate (grade 2+) in 38. The mean (standard deviation [SD]) TAD measured in late diastole was $36.5(5.2) \mathrm{mm}$ and the mean (SD) indexed TAD (TAD/body surface area) was $24.1(3.8) \mathrm{mm} / \mathrm{m}^{2}$.

\section{Surgical procedure}

Surgery was performed under moderate hypothermia and cardiopulmonary bypass. Mitral valve surgery and concomitant procedures were performed with aortic crossclamping and either repeated antegrade or antegrade and retrograde cold cardioplegia. Only one patient in the early period underwent left atrial plication for a huge left atrium.

To repair the tricuspid valve, tricuspid annuloplasty using a flexible ring was performed in 52 patients (all in the late period). A Duran-Medtronic ring (Medtronic, Minneapolis, MN, USA) was used in seven patients and a Cosgrove-Edwards ring (Edwards Life Sciences, Irvine, CA, USA) in 45 patients. With regard to the size of the ring, a 33-mm Duran ring or \#30-mm Cosgrove ring was used for male patients, while a \#31-mm Duran ring or \#28-mm Cosgrove ring was used for female patients. Procedures other than ring annuloplasty, such as edge-to-edge repair, were not performed for the tricuspid valve. 
Table 1 The baseline characteristics of the patients

\begin{tabular}{|c|c|c|c|c|}
\hline Operative period characteristics & All $(n=125)$ & Early period $(1987-1997, n=54)$ & Late period $(1998-2006 n=71)$ & $P$ value \\
\hline Age (years) & $58.0 \pm 12.0$ & $53.4 \pm 11.7$ & $61.5 \pm 11.1$ & $<0.001$ \\
\hline Age $>50$ years & $103(82.4 \%)$ & $40(74.1 \%)$ & $63(88.7 \%)$ & 0.06 \\
\hline Male sex & $54(43.2 \%)$ & $25(46.3 \%)$ & $29(40.8 \%)$ & 0.59 \\
\hline $\operatorname{BSA}\left(\mathrm{m}^{2}\right)$ & $1.53 \pm 0.17$ & $1.50 \pm 0.15$ & $1.55 \pm 0.17$ & 0.15 \\
\hline $\mathrm{BSA} \geq 1.50 \mathrm{~m}^{2}$ & $61(48.8 \%)$ & $19(35.2 \%)$ & $42(59.2 \%)$ & 0.008 \\
\hline Rheumatic disease & $69(55.2 \%)$ & $39(72.2 \%)$ & $30(42.3 \%)$ & 0.001 \\
\hline Mitral stenosis dominant & $56(44.8 \%)$ & $34(63.0 \%)$ & $22(31.0 \%)$ & 0.001 \\
\hline Acute onset of MV disease ( $<1$ month) & $10(8.0 \%)$ & $3(5.6 \%)$ & $7(9.9 \%)$ & 0.512 \\
\hline Concomitant aortic valve surgery & $44(35.2 \%)$ & $19(35.2 \%)$ & $25(35.2 \%)$ & 1.0 \\
\hline Redo surgery & $20(16.0 \%)$ & $11(20.4 \%)$ & $9(12.7 \%)$ & 0.25 \\
\hline Pulmonary hypertension & $63(50.4 \%)$ & $36(66.7 \%)$ & $27(38.0 \%)$ & 0.002 \\
\hline Atrial fibrillation & $70(56.0 \%)$ & $38(70.4 \%)$ & $32(45.1 \%)$ & 0.005 \\
\hline MV repair & $11(8.8 \%)$ & $1(1.9 \%)$ & $10(14.1 \%)$ & 0.02 \\
\hline Maze procedure & $6(4.8 \%)$ & $1(1.9 \%)$ & $5(7.0 \%)$ & 0.23 \\
\hline Preoperative TR $0: 1+: 2+$ & $5: 82: 38$ & $4: 37: 13$ & $1: 45: 25$ & 0.13 \\
\hline TAD (mm) & $36.5 \pm 5.2$ & $36.0 \pm 6.1$ & $36.9 \pm 4.3$ & 0.34 \\
\hline $\mathrm{TAD} \geq 35 \mathrm{~mm}$ & $89(71.2 \%)$ & $32(59.3 \%)$ & $57(80.3 \%)$ & 0.01 \\
\hline Indexed TAD $\left(\mathrm{mm} / \mathrm{m}^{2}\right)$ & $24.1 \pm 3.8$ & $24.1 \pm 4.5$ & $24.1 \pm 3.2$ & 0.91 \\
\hline Indexed TAD $\geq 21 \mathrm{~mm} / \mathrm{m}^{2}$ & $95(76.0 \%)$ & $36(66.7 \%)$ & $59(83.1 \%)$ & 0.03 \\
\hline $\mathrm{LAD}(\mathrm{mm})$ & $55.7 \pm 10.4$ & $57.0 \pm 10.0$ & $54.6 \pm 10.6$ & 0.21 \\
\hline $\mathrm{LAD} \geq 60 \mathrm{~mm}$ & $45(36.0 \%)$ & $22(40.7 \%)$ & $23(32.4 \%)$ & 0.34 \\
\hline Indexed LAD $\left(\mathrm{mm} / \mathrm{m}^{2}\right)$ & $36.8 \pm 7.7$ & $38.3 \pm 7.8$ & $35.7 \pm 7.5$ & 0.06 \\
\hline Indexed LAD $\geq 35 \mathrm{~mm} / \mathrm{m}^{2}$ & $72(57.6 \%)$ & $36(66.7 \%)$ & $36(50.7 \%)$ & 0.07 \\
\hline LVDd (mm) & $55.1 \pm 9.1$ & $54.0 \pm 10.3$ & $56.0 \pm 8.1$ & 0.23 \\
\hline LVDd $\geq 55 \mathrm{~mm}$ & $62(49.6 \%)$ & $24(44.4 \%)$ & $38(49.6 \%)$ & 0.32 \\
\hline Indexed LVDd $\left(\mathrm{mm} / \mathrm{m}^{2}\right)$ & $36.3 \pm 6.1$ & $36.1 \pm 7.0$ & $36.4 \pm 5.3$ & 0.79 \\
\hline Indexed LVDd $\geq 35 \mathrm{~mm} / \mathrm{m}^{2}$ & $63(50.4 \%)$ & $25(46.3 \%)$ & $38(53.5 \%)$ & 0.42 \\
\hline LVDs (mm) & $36.2 \pm 7.3$ & $36.2 \pm 7.9$ & $36.3 \pm 6.9$ & 0.93 \\
\hline LVDs $\geq 40 \mathrm{~mm}$ & $39(31.2 \%)$ & $20(37.0 \%)$ & $19(26.8 \%)$ & 0.22 \\
\hline Indexed LVDs $\left(\mathrm{mm} / \mathrm{m}^{2}\right)$ & $23.9 \pm 5.0$ & $24.2 \pm 5.2$ & $23.7 \pm 4.9$ & 0.60 \\
\hline Indexed LVDs $\geq 25 \mathrm{~mm} / \mathrm{m}^{2}$ & $44(35.2 \%)$ & $23(42.6 \%)$ & $21(29.6 \%)$ & 0.13 \\
\hline LVEF & $0.66 \pm 0.08$ & $0.66 \pm 0.08$ & $0.66 \pm 0.09$ & 0.91 \\
\hline LVEF $<0.65$ & $50(40.0 \%)$ & $24(44.4 \%)$ & $26(36.6 \%)$ & 0.376 \\
\hline Tricuspid valve repair & $52(41.6 \%)$ & $0(0 \%)$ & $52(73.2 \%)$ & $<0.001$ \\
\hline Follow-up period (years) & $12.2 \pm 6.0$ & $16.0 \pm 6.7$ & $9.5 \pm 3.3$ & $<0.001$ \\
\hline
\end{tabular}

The data are shown as the mean \pm standard deviation or number (frequency)

$B S A$ body surface area, $M V$ mitral valve, $T R$ tricuspid regurgitation, $L A D$ left atrial dimension, $L V D d$ left ventricular diastolic dimension, $L V D s$ left ventricular systolic dimension, $L V E F$ left ventricular ejection fraction, $T A D$ tricuspid annular diameter

\section{Echocardiographic measurements}

Preoperative transthoracic echocardiography, including two-dimensional echocardiographic and Doppler color flow examinations, was performed in all of the patients by the same experienced operator (M.H.) during the week before surgery.

TR was assessed by Doppler color flow mapping images of the regurgitant jet and pulsed wave Doppler evidence of systolic flow reversal in the inferior vena cava or hepatic veins. The view with maximal spatial distribution of the regurgitant jet was selected, and the jet and right atrial areas were measured in the same frame by planimetry. The severity of TR was graded as follows: none (grade 0 ), no regurgitant jet; mild (grade $1+$ ), a jet area of $<20 \%$ of the right atrial area; moderate (grade $2+$ ), a jet area of 20-33\% of the right atrial area; and severe (grade 3+), a jet area of $>33 \%$ of the right atrial area [3, 13, 14]. Patients 
with severe preoperative TR were excluded from the study. If the estimated ratio of the jet area to the right atrial area was close to a cutoff point, the grade of jet eccentricity was increased to the next higher value. Systolic flow reversal in the inferior vena cava or hepatic veins on pulsed wave Doppler images was considered to indicate at least moderate TR, regardless of the other findings [3, 14].

In addition to valvular examinations and routine measurements (e.g., left ventricular and left atrial dimensions), the TAD was measured in the apical four-chamber view in late diastole at the time of maximal tricuspid valve opening, as recommended by Foale et al. [15] (Fig. 2).

Postoperative transthoracic echocardiography was performed before discharge and every year thereafter.

\section{Follow-up}

All of the patients were followed up at the Osaka General Medical Center at 3, 6, and 12 months postoperatively. After 1 year, most patients ( $>90 \%)$ were followed up at 3or 6-month intervals at the Osaka General Medical Center; the other patients were followed up by local cardiologists. Most patients underwent echocardiography, which was performed by the same experienced operator (M.H.), each year at the Osaka General Medical Center. With the exception of five patients who were lost to follow-up at $>5$ years after surgery, follow-up is ongoing for all of the surviving patients.

The follow-up for severe TR was censored when the patient died without severe postoperative TR. Although there were three patients whose TR diminished from severe (grade $3+$ ) to moderate (grade $2+$ ), probably due to enhanced medication, the follow-up of their TR was discontinued when severe TR was first observed.

\section{Statistical analysis}

Continuous and categorical variables are reported as the mean and standard deviations (SD), and as frequencies with percentages, respectively. Continuous variables were compared using Student's $t$ test. Categorical variables were compared using Fisher's exact test if any cell had a count of less than 5 in a contingency table; otherwise, the Chisquared test was used. Curves for survival and freedom from severe TR were estimated using the Kaplan-Meier method and compared using the log-rank test. A univariate analysis using a log-rank test was used to identify the risk factors for severe TR. A multivariate analysis, which included the risk factors with $P$ values of $<0.2$ in the univariate analysis, was adjusted using the Cox proportional hazard regression model with variable selection (such as forward, backward, and stepwise selection). Hazard ratios and $95 \%$ confidence intervals (CIs) were estimated using

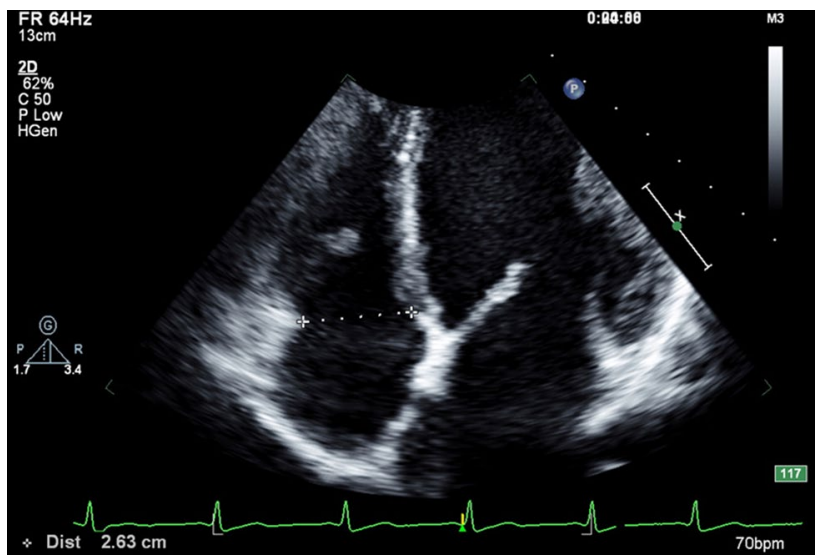

Fig. 2 The measurement of the tricuspid annular diameter

the Cox proportional hazard regression model. Changes in the TAD from the preoperative period to the postoperative period were compared between groups by a two-way repeated-measures analysis of variance (ANOVA) that included the main effects of the group and time and the interaction effect between them.

All of the significance tests were two sided and $P$ values of $<0.05$ were considered to indicate statistical significance. All of the statistical analyses were performed using the SPSS 21.0 software program (IBM, Armonk, NY, USA).

\section{Results}

\section{Survival}

The follow-up period ranged from 1.0 to 24.7 years (mean 12.3 years; median 11.7 years). Late death occurred in 38 patients at 1-23 years after surgery. The causes of death included heart failure $(n=8)$, malignancy $(n=6)$, septicemia $(n=4)$, cerebral bleeding $(n=3)$, pneumonia $(n=3)$, renal failure $(n=2)$, cerebral infarction $(n=1)$, and bowel necrosis $(n=1)$; the cause of death was unknown in 10 patients. Six of the 8 patients who died of heart failure had severe TR at the time of death. Five patients were lost to follow-up at 5-18 years.postoperatively. The survival rates at postoperative years $5,10,15$, and 20 were $91,81,64$, and $59 \%$, respectively. The survival of the patients in the early and late periods did not differ to a statistically significant extent $(P=0.90)$.

\section{The rate of postoperative freedom from severe $T R$ in the earl-period patients}

Nineteen of the 54 early-period patients (none of whom underwent TVR) developed severe postoperative TR. The 


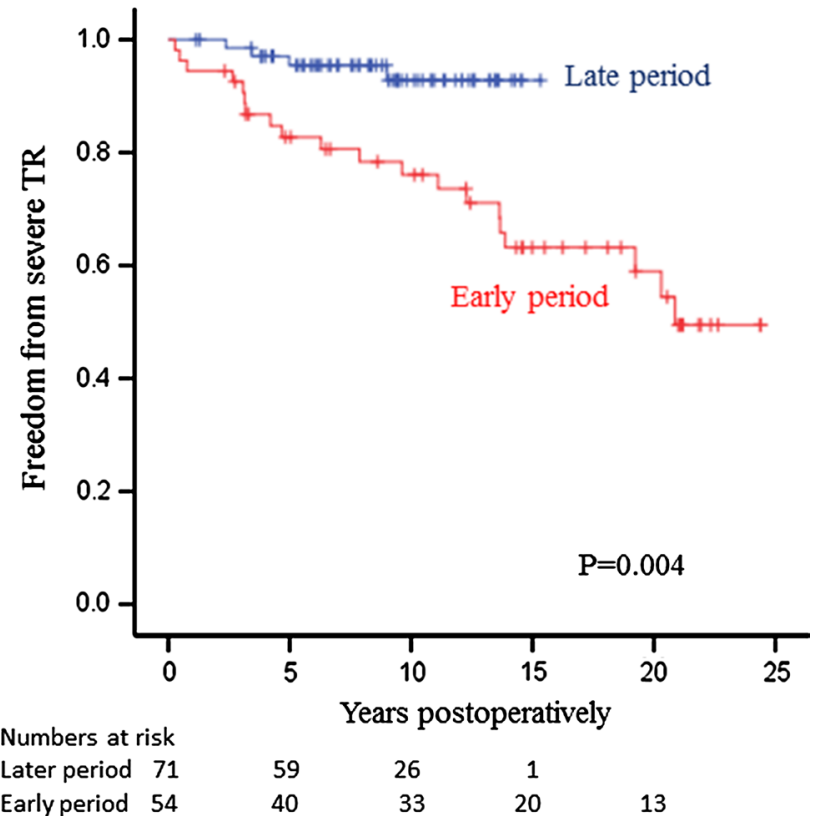

Fig. 3 Freedom from severe TR in patients of the early and late periods. $T R$ tricuspid regurgitation. $P=0.004$ (log-rank test)

rates of freedom from severe TR at postoperative years $5,10,15$, and 20 were $83,76,63$, and $59 \%$, respectively (Fig. 3). Three patients in the early period underwent TVR during the follow-up period. All of these three patients underwent aortic valve replacement and tricuspid valve annuloplasty (two for severe TR and one for moderate TR). One of these patients died of septicemia during the perioperative period.

\section{The risk factors for severe postoperative $\mathrm{TR}$ in the early-period patients}

A univariate analysis showed that preoperative moderate (grade 2+) TR, atrial fibrillation, an indexed left atrial diameter of $\geq 35 \mathrm{~mm} / \mathrm{m}^{2}$, and $\geq 50$ years of age were significantly associated with severe postoperative TR (all $P<0.05$, log-rank test) (Table 2). Seven variables, including a dominant lesion of mitral stenosis, a body surface area of $\geq 1.50 \mathrm{~m}^{2}$, and a left ventricular systolic dimension of $\geq 40 \mathrm{~mm}$, in addition to the four significant variables listed above, showed a $P$ value of $<0.2$. These factors were entered into a multivariate analysis using the Cox proportional-hazards model with variable selection methods (forward, backward, and stepwise methods). All of the methods provided the same result: preoperative moderate (grade 2+) TR was a significant risk factor for severe postoperative TR (Table 2). The rates for freedom from severe TR at postoperative years 5,10 , and 15 were 59,47 , and $24 \%$, respectively, for the 13 patients with grade $2+\mathrm{TR}$, and 90,84 , and $74 \%$, respectively, for the 41 patients with grade $\leq 1+$ TR (Fig. 4).

\section{Freedom from severe TR in the late-period patients}

Four of the late-period patients developed severe TR. The rates for freedom from severe TR at postoperative years 5, 10, and 15 were 96, 93, and $93 \%$, respectively (Fig. 1). The rate of freedom from severe TR in the late-period patients was significantly higher than that in the earlyperiod patients $(P=0.004)$. One patient in the late period underwent TVR with a prosthetic ring during the follow-up period for severe TR.

Table 3 shows the characteristics of the 52 patients who underwent TVR and the 19 patients who did not in the late period. Besides a larger TAD, the patients who underwent TVR had a greater number of potential risk factors for severe postoperative TR (such as grade $2+$ TR, atrial fibrillation, and a greater left atrial dimension) in the early period than the patients who did not undergo TVR. Nonetheless, none of the patients who underwent TVR developed severe postoperative TR. In contrast, four of the 19 patients who did not undergo TVR developed severe postoperative TR. The rates of freedom from severe TR at 5 and 10 years were 100 and $100 \%$, respectively, in the patients who underwent TVR, and 83 and $77 \%$, respectively, in the patients who did not undergo TVR $(P=0.001$, Fig. 5). Table 4 shows the characteristics of each of the four patients who developed severe TR in the late period. The TAD ranged from 27 to $35 \mathrm{~mm}$, and all four patients had a TAD of $\leq 35 \mathrm{~mm}$. Similarly, the indexed TAD ranged from 17.9 to $22.2 \mathrm{~mm}$, and three of the four patients had an indexed TAD of $<21 \mathrm{~mm} / \mathrm{m}^{2}$.

\section{Serial changes in the TAD}

Because the preoperative and postoperative TAD values were serially measured in most patients, the preoperative and postoperative indexed TAD values were compared among three groups of patients, who were categorized as follows. Group 1 included patients who did not undergo TVR and who did not develop severe postoperative TR ( $n=39$; early period, $n=24$; late period, $n=15$ ). Group 2 included patients who did not undergo TVR and who developed severe postoperative TR $(n=18$; early period, $n=14$; late period $n=4$ ). Group 3 included patients who underwent TVR (none of them developed severe postoperative TR) ( $n=51$, all in the late period). Seventeen patients in whom the postoperative TAD was not serially measured were excluded from this analysis. In groups 1 and 3, the value that was used for the postoperative TAD was obtained at the last follow-up examination (group 1: postoperative 
Table 2 The univariate and multivariate analysis of risk factors for severe TR after mitral valve surgery in the early-period patients (1987-1997)

\begin{tabular}{|c|c|c|c|c|c|}
\hline \multirow[t]{2}{*}{ Factors } & \multirow{2}{*}{$\begin{array}{l}\text { Number } \\
\text { (frequency, \%) }\end{array}$} & \multicolumn{2}{|l|}{ Univariate analysis } & \multicolumn{2}{|c|}{ Multivariate analysis } \\
\hline & & $\operatorname{HR}(95 \% \mathrm{CI})^{\mathrm{a}}$ & $P$ value ${ }^{\mathrm{c}}$ & $\begin{array}{l}\text { Adjusted HR } \\
(95 \% \mathrm{CI})^{\mathrm{a}}\end{array}$ & $\begin{array}{l}\text { Adjusted } \\
P \text { value }\end{array}$ \\
\hline Age $>50$ years & $40(74.1)$ & $4.28(0.99-8.5)$ & 0.034 & & \\
\hline Male sex & $25(46.3)$ & $0.71(0.29-1.75)$ & 0.457 & & \\
\hline $\mathrm{BSA} \geq 1.50 \mathrm{~m}^{2}$ & $19(35.2)$ & $0.50(0.18-1.39)$ & 0.175 & & \\
\hline Rheumatic disease & $39(72.2)$ & $2.15(0.63-7.37)$ & 0.210 & & \\
\hline Mitral stenosis dominant & $34(63.0)$ & $2.27(0.65-6.79)$ & 0.133 & & \\
\hline Acute onset of MV disease ( $<1$ month) & $3(5.6)$ & $\mathrm{NE}^{\mathrm{b}}$ & 0.263 & & \\
\hline Concomitant aortic valve surgery & $19(35.2)$ & $1.72(0.69-4.26)$ & 0.236 & & \\
\hline Redo surgery & $11(20.4)$ & $0.89(0.30-2.68)$ & 0.841 & & \\
\hline Pulmonary hypertension & $36(66.7)$ & $1.42(0.54-3.73)$ & 0.469 & & \\
\hline Atrial fibrillation & $38(70.4)$ & $4.91(1.14-21.21)$ & 0.018 & $3.97(0.90-17.5)$ & 0.068 \\
\hline MV repair & $1(1.9)$ & $\mathrm{NE}^{\mathrm{b}}$ & 0.495 & & \\
\hline Maze procedure & $1(1.9)$ & $\mathrm{NE}^{\mathrm{b}}$ & 0.495 & & \\
\hline Moderate $(2+) \mathrm{TR}$ & $13(24.1)$ & $3.89(1.54-9.84)$ & 0.002 & $3.08(1.21-7.82)$ & 0.018 \\
\hline $\mathrm{TAD} \geq 35 \mathrm{~mm}$ & $32(59.3)$ & $1.39(0.57-3.42)$ & 0.470 & & \\
\hline Indexed TAD $\geq 21 \mathrm{~mm} / \mathrm{m}^{2}$ & $36(66.7)$ & $1.48(0.57-3.86)$ & 0.424 & & \\
\hline $\mathrm{LAD} \geq 60 \mathrm{~mm}$ & $22(40.7)$ & $1.66(0.69-4.02)$ & 0.253 & & \\
\hline Indexed $\mathrm{LAD} \geq 35 \mathrm{~mm} / \mathrm{m}^{2}$ & $36(66.7)$ & $3.87(1.13-13.26)$ & 0.020 & & \\
\hline LVDd $\geq 55 \mathrm{~mm}$ & $24(44.4)$ & $0.59(0.24-1.49)$ & 0.262 & & \\
\hline Indexed LVDd $\geq 35 \mathrm{~mm} / \mathrm{m}^{2}$ & $25(46.3)$ & $0.92(0.38-2.23)$ & 0.854 & & \\
\hline LVDs $\geq 40 \mathrm{~mm}$ & $20(37.0)$ & $0.52(0.19-1.43)$ & 0.197 & & \\
\hline Indexed LVDs $\geq 25 \mathrm{~mm} / \mathrm{m}^{2}$ & $23(42.6)$ & $1.20(0.50-2.89)$ & 0.691 & & \\
\hline LVEF $<0.65$ & $24(44.4)$ & $0.91(0.37-2.24)$ & 0.843 & & \\
\hline
\end{tabular}

$T R$ tricuspid regurgitation, $H R$ hazard ratio, $B S A$ body surface area, $M V$ mitral valve, $L A D$ left atrial dimension, $L V D d$ left ventricular diastolic dimension, $L V D$ s left ventricular systolic dimension, $L V E F$ left ventricular ejection fraction, $T A D$ tricuspid annular diameter, $C I$ confidence interval, $N E$ not estimable

${ }^{\text {a }}$ The HRs and $95 \%$ CIs were estimated using the Cox proportional-hazards model

b The numbers of patients with an acute onset of MV disease ( $<1$ month), MV repair, and the maze procedure were small. Thus, the parameters of these factors were not estimable

c The $P$ values were based on the log-rank test

year, $13.7 \pm 6.0$; group 3: postoperative year, $8.2 \pm 3.6)$. In group 2 , the value that was used for the postoperative TAD was obtained at the time of the diagnosis of severe postoperative TR (postoperative year, $9.0 \pm 6.2$ ).

The changes in the indexed TAD values before and after surgery differed among the groups $(P<0.001$ for an interaction effect between group and time in a two-way repeatedmeasures ANOVA). Specifically, the preoperative indexed TAD values of the patients in group 3 were larger than those in groups 1 and 2 because TVR was performed in patients with a large TAD. The indexed TAD was increased after surgery in groups 1 and 2, but was decreased after surgery in group 3 . The postoperative indexed TAD values of the patients in group 2 were larger than those in groups 1 and 3 (Fig. 6).

\section{Discussion}

The findings of the present study were as follows. First, a relatively high rate of patients without severe preoperative TR developed severe TR after mitral valve surgery if the tricuspid valve was left untouched. Additionally, moderate preoperative TR was the most significant risk factor for severe postoperative TR. Second, the aggressive application of TVR using a prosthetic ring prevented the development of severe postoperative TR for a long period of time. Third, our indication, tricuspid annular dilatation as measured by a preoperative echocardiogram, might not be a good indicator of whether patients undergoing mitral valve surgery should undergo concomitant TVR. 


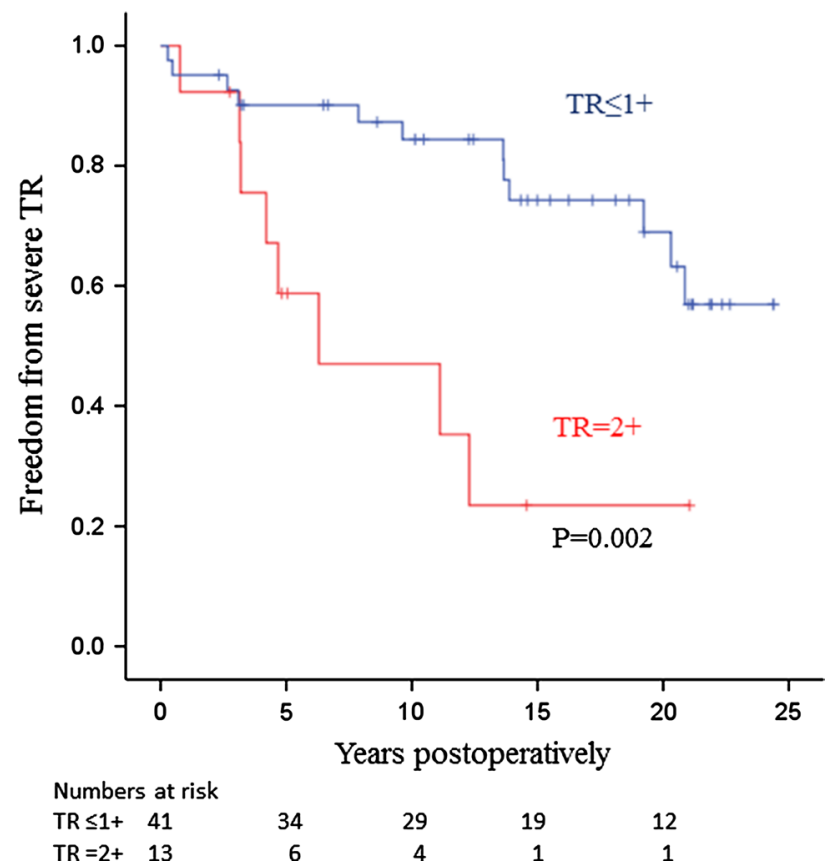

Fig. 4 Freedom from severe TR in the early-period patients with grade $2+$ and $\leq 1+$ TR. The rate of freedom from severe TR in patients with grade $2+$ TR was significantly lower than that in patients with grade $\leq 1+\mathrm{TR}(P=0.002$; log-rank test). $T R$ tricuspid regurgitation

\section{The prevalence and predictors of significant postoperative TR after mitral valve surgery}

Significant TR has previously been reported to develop at a relatively high number of cases after mitral valve surgery $[3,5,8,9,16,17]$. The risk factors for postoperative TR in these studies included older age $[3,17]$, the grade of preoperative TR [8, 17], atrial fibrillation [8, 9, 16], a huge left atrium $[8,9]$, a long time from the onset of mitral valve disease to surgery [9], rheumatic changes of the tricuspid valve [9], and a low ejection fraction [16]. In the present study, the rate of severe postoperative TR at 20 years among the early-period patients (none of whom underwent TVR) was $41 \%$. The univariate analysis revealed that the predictors of severe TR were moderate preoperative TR, a large left atrial dimension, atrial fibrillation, and older age. Our results are therefore similar to those of previous studies.

\section{The effectiveness of tricuspid valve repair with a prosthetic ring for less than severe TR in patients who underwent mitral valve surgery}

In the late period of this study, we aggressively applied TVR using a prosthetic ring in 52 of the 71 patients who underwent mitral valve surgery. Although our indication for TVR was tricuspid annular dilatation (TAD $\geq 35 \mathrm{~mm}$ ), these patients also had other risk factors, such as moderate TR, atrial fibrillation, rheumatic disease, pulmonary hypertension, and a large left atrium (Table 3). Nonetheless, the rate of freedom from severe TR was $100 \%$ at 15 years. Thus, prophylactic TVR using a prosthetic ring appears to be effective in preventing the development of severe postoperative TR in patients without severe preoperative TR.

\section{The validity of tricuspid annular dilatation as an indication for TVR}

In the present study, we attempted to examine the validity of our indication (preoperative tricuspid annular dilatation) for prophylactic TVR in patients undergoing mitral valve surgery. In the early-period patients (none of whom underwent TVR), tricuspid annular dilatation (a TAD of $\geq 35 \mathrm{~mm}$ or an indexed TAD of $\geq 21 \mathrm{~mm} / \mathrm{m}^{2}$ ) was not a risk factor for severe postoperative TR (Table 2). The logrank test did not show a significant difference in the rate of freedom from severe postoperative TR between patients with large and small TAD values (Fig. 7a, b). Furthermore, in the late-period patients in whom tricuspid annular dilatation (TAD $\geq 35 \mathrm{~mm}$ ) was used as an indicator for TVR, the cumulative incidence of severe TR at 10 years in patients who did not undergo tricuspid repair was $23 \%$. We are therefore of the opinion that tricuspid annular dilatation might not be a valid indicator of whether patients undergoing mitral valve surgery should undergo concomitant TVR. This conclusion may be surprising because many surgeons believe that tricuspid annular dilatation is an indicator of TVR in patients undergoing mitral valve surgery, because the guidelines for the management of valvular heart disease suggest that the performance of TVR in such patients.

Tricuspid annular dilatation, as measured by preoperative or intraoperative echocardiography, has been recommended as an indication for TVR by several authors [13, $18,19]$ based on the observation that the TAD was correlated with the severity of TR. Following this recommendation, tricuspid annular dilatation was used as an indication for TVR at the time of mitral valve surgery by Tager et al. [20] (TAD $\geq 30 \mathrm{~mm}$ ), Colombo et al. [21] (indexed $\mathrm{TAD} \geq 21 \mathrm{~mm} / \mathrm{m}^{2}$ ), Van de Veire et al. [22] (TAD $\geq 40 \mathrm{~mm}$ ), and Calafiore et al. [23] (systolic TAD $\geq 24 \mathrm{~mm}$ ). Dreyfus et al. [6] performed TVR in patients with a TAD of $\geq 70 \mathrm{~mm}$, which was measured intraoperatively from the anteroseptal to the anteroposterior commissures in the arrested heart. These authors concluded that tricuspid annular dilatation was an appropriate indicator of whether patients undergoing mitral valve surgery should undergo concomitant TVR. However, a detailed examination of the data from the above-mentioned studies might not fully support this conclusion. In the study by Dreyfus et al. [6], 55 
Table 3 The characteristics of patients who did underwent TVR in the late period and those who did not undergo TVR

\begin{tabular}{|c|c|c|c|}
\hline Characteristics & Underwent TVR $(n=52)$ & Did not undergo TVR $(n=19)$ & $P$ value \\
\hline Age (years) & $61.9 \pm 9.5$ & $60.3 \pm 14.8$ & 0.59 \\
\hline Male sex & $19(36.5 \%)$ & $10(52.6 \%)$ & 0.22 \\
\hline Age $>50$ years & $48(92.3 \%)$ & $15(78.9 \%)$ & 0.12 \\
\hline $\operatorname{BSA}\left(\mathrm{m}^{2}\right)$ & $1.55 \pm 0.18$ & $1.52 \pm 0.16$ & 0.45 \\
\hline Rheumatic disease & $28(53.8 \%)$ & $2(10.5 \%)$ & 0.001 \\
\hline Mitral stenosis dominant & $21(40.4 \%)$ & $1(5.3 \%)$ & 0.004 \\
\hline Acute onset of MV disease ( $<1$ month) & $3(5.8 \%)$ & $4(21.1 \%)$ & 0.08 \\
\hline Concomitant aortic valve surgery & $18(34.6 \%)$ & $7(36.8 \%)$ & 0.87 \\
\hline Redo surgery & $8(15.4 \%)$ & $1(5.3 \%)$ & 0.43 \\
\hline Pulmonary hypertension & $25(48.1 \%)$ & $2(10.5 \%)$ & 0.005 \\
\hline Atrial fibrillation & $30(57.7 \%)$ & $2(10.5 \%)$ & $<0.001$ \\
\hline MV repair & $4(7.7 \%)$ & $6(31.6 \%)$ & 0.01 \\
\hline Maze procedure & $5(9.6 \%)$ & $0(0 \%)$ & 0.32 \\
\hline Preoperative TR $0: 1+: 2+$ & $0: 27: 25$ & $1: 18: 0$ & $<0.001$ \\
\hline TAD (mm) & $38.5 \pm 3.0$ & $32.5 \pm 4.3$ & $<0.001$ \\
\hline $\mathrm{TAD} \geq 35 \mathrm{~mm}$ & $51(98.1 \%)$ & $6(31.6 \%)$ & $<0.001$ \\
\hline Indexed TAD $\left(\mathrm{mm} / \mathrm{m}^{2}\right)$ & $25.0 \pm 2.8$ & $21.5 \pm 2.9$ & $<0.001$ \\
\hline Indexed TAD $\geq 21 \mathrm{~mm} / \mathrm{m}^{2}$ & $49(94.2 \%)$ & $10(52.6 \%)$ & $<0.001$ \\
\hline $\mathrm{LAD}(\mathrm{mm})$ & $56.9 \pm 9.6$ & $48.4 \pm 10.8$ & 0.002 \\
\hline $\mathrm{LAD} \geq 60 \mathrm{~mm}$ & $21(40.4 \%)$ & $2(10.5 \%)$ & 0.022 \\
\hline Indexed LAD $\left(\mathrm{mm} / \mathrm{m}^{2}\right)$ & $37.1 \pm 7.2$ & $32.0 \pm 7.1$ & 0.011 \\
\hline Indexed LAD $>35 \mathrm{~mm} / \mathrm{m}^{2}$ & $30(57.7 \%)$ & $6(31.6 \%)$ & 0.05 \\
\hline LVDd (mm) & $55.5 \pm 8.9$ & $57.2 \pm 5.4$ & 0.43 \\
\hline Indexed LVDd $\left(\mathrm{mm} / \mathrm{m}^{2}\right)$ & $35.9 \pm 5.5$ & $37.9 \pm 4.7$ & 0.15 \\
\hline LVDs (mm) & $36.2 \pm 7.3$ & $36.4 \pm 5.7$ & 0.91 \\
\hline Indexed LVDs $\left(\mathrm{mm} / \mathrm{m}^{2}\right)$ & $23.5 \pm 5.1$ & $24.2 \pm 4.5$ & 0.61 \\
\hline LVEF & $0.65 \pm 0.08$ & $0.69 \pm 0.10$ & 0.13 \\
\hline
\end{tabular}

$T V R$ tricuspid valve repair, $B S A$ body surface area, $M V$ mitral valve, $L A D$ left atrial dimension, $L V D d$ left ventricular diastolic dimension, $L V D s$ left ventricular systolic dimension, $L V E F$ left ventricular ejection fraction, TAD tricuspid annular diameter

out of 163 patients with a TAD of $<70 \mathrm{~mm}$ developed grade $3+$ to $4+$ TR at a mean follow-up time of 4.8 years. Moreover, the follow-up period in some of the studies appears to be insufficient $[22,23]$.

In contrast, other studies have reported that preoperative tricuspid annular dilatation is not a pivotal factor for the progression of TR after mitral valve surgery [24, 25]. Goldstone et al. [17] recently reported that older age and the grade of preoperative TR were independent predictors of the postoperative progression of TR in patients undergoing mitral valve repair for mitral valve prolapse with TR that was assessed as being less than severe. However, they reported that when limited to patients with mild TR (or those without TR), the indexed TAD was the only significant risk factor.

We also analyzed the risk factors of 41 patients in the early period with mild or none (grade $1+$ or 0 ) preoperative TR. We found that atrial fibrillation and a huge left atrium (left atrial dimension $\geq 35 \mathrm{~mm}$ ) were significant risk factors for severe postoperative TR, but that tricuspid annular dilatation (a TAD of $\geq 35 \mathrm{~mm}$ or an indexed TAD of $\geq 21 \mathrm{~mm} / \mathrm{m}^{2}$ ) was not a risk factor in a univariate analysis (log-rank test). Because of the small number of patients, our study does not have sufficient statistical power to prove that tricuspid annular dilatation is not a valid indicator of tricuspid valve surgery. We believe that the validity of tricuspid annular dilatation as an indicator of whether patients should undergo TVR needs to be re-evaluated.

\section{The mechanisms underlying secondary TR after mitral valve surgery}

An understanding of the mechanisms underlying secondary TR is improving based on the results of the detailed analysis of the structure of the tricuspid valve. Tricuspid annular dilatation is commonly observed in patients with severe TR [14, 26-28]. We also showed that the TAD was significantly increased in patients who developed severe postoperative TR at the time of its development (Fig. 6). 


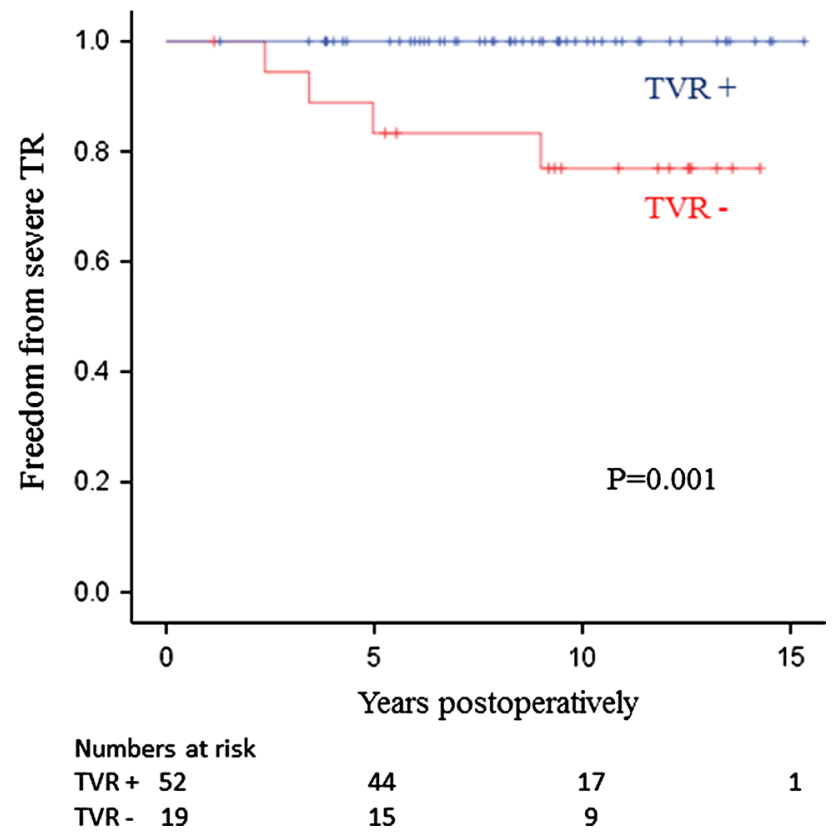

Fig. 5 Freedom from severe TR in the late-period patients who underwent TVR and those who did not undergo TVR. None of the patients who underwent TVR developed severe TR. TR tricuspid regurgitation, $T V R$ tricuspid valve repair. $P=0.001$ (log-rank test)

In addition, the tethering of the tricuspid valve leaflets may play a major role in the development of secondary TR. Right ventricular enlargement due to mitral valve disease causes tricuspid annular dilatation and the displacement of the papillary muscles, leading to the tethering of the tricuspid valve leaflets. This results in inadequate leaflet coaptation $[29,30]$. A recent study used three-dimensional echocardiography to evaluate patients with secondary TR and reported that the tricuspid annulus was not only dilated, but also flattened and circular in patients with secondary TR [31].

However, the reason why these changes in the tricuspid valve structure occur after mitral valve surgery is not clear. In the present study, we excluded patients with recurrence or in which the mitral valve lesions were insufficiently repaired and those who developed abnormal prosthetic valve function [32]. Thus, the tricuspid valve was unlikely to have been affected by residual mitral valve disease. The tricuspid valve was also unlikely to have been affected by persistent pulmonary hypertension after mitral valve surgery. This hypothesis is based on our finding that postoperative pulmonary hypertension, as assessed by follow-up echocardiography, was not a significant risk factor for severe postoperative TR in our univariate analysis $[P=0.39$ (logrank test); hazard ratio $=1.48, P=0.40$ (Cox hazards model)]. Previous studies $[1,6]$ have also reported similar findings.

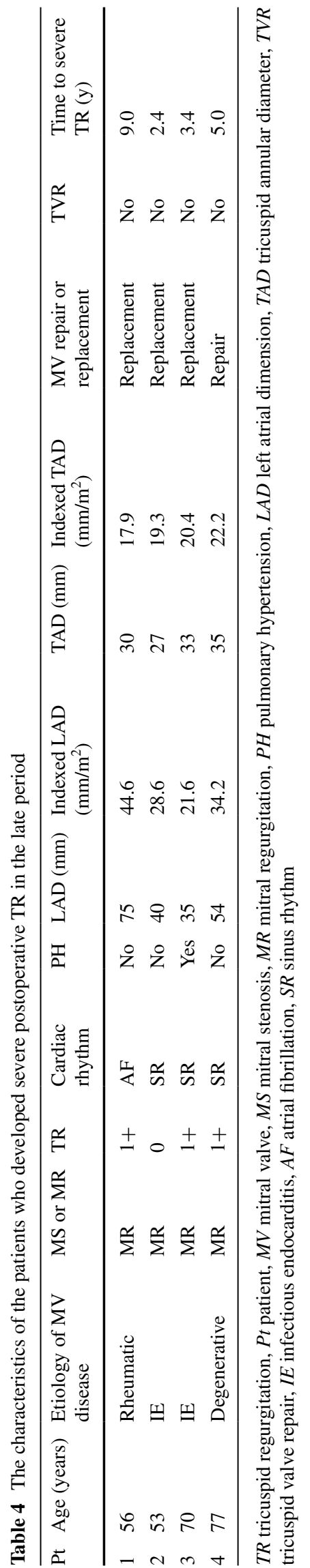



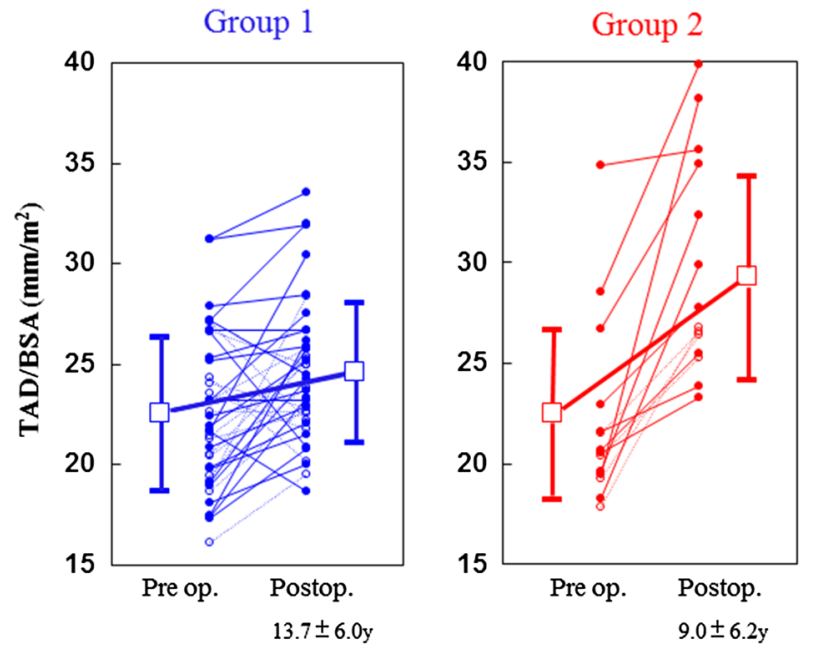

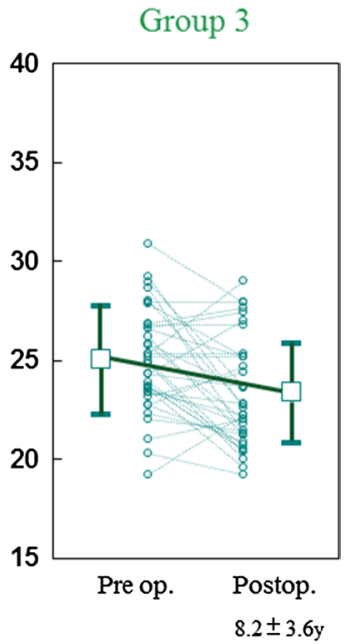

Fig. 6 Changes in the indexed tricuspid annular diameter before and after surgery. Group 1 consisted of 39 patients who did not undergo TVR and who did not develop severe postoperative TR. Group 2 consisted of 18 patients who did not undergo tricuspid valve surgery and who developed severe postoperative TR. Group 3 consisted of 51 patients who underwent TVR (none of them developed severe postoperative TR). Closed circles indicate the early-period patients; open circles indicate the late-period patients. Open squares and bars indicate the means and standard deviations for each group of patients. A two-way repeated ANOVA showed that the $P$ values for the main effects of group and time were $P=0.03$ and $P<0.001$, respectively; while the $P$ value for the interaction effect between them was $P<0.001$. See the text for more information about the comparisons between the groups. $B S A$ body surface area, $T R$ tricuspid regurgitation, $T V R$ tricuspid valve repair, TAD tricuspid annular diameter

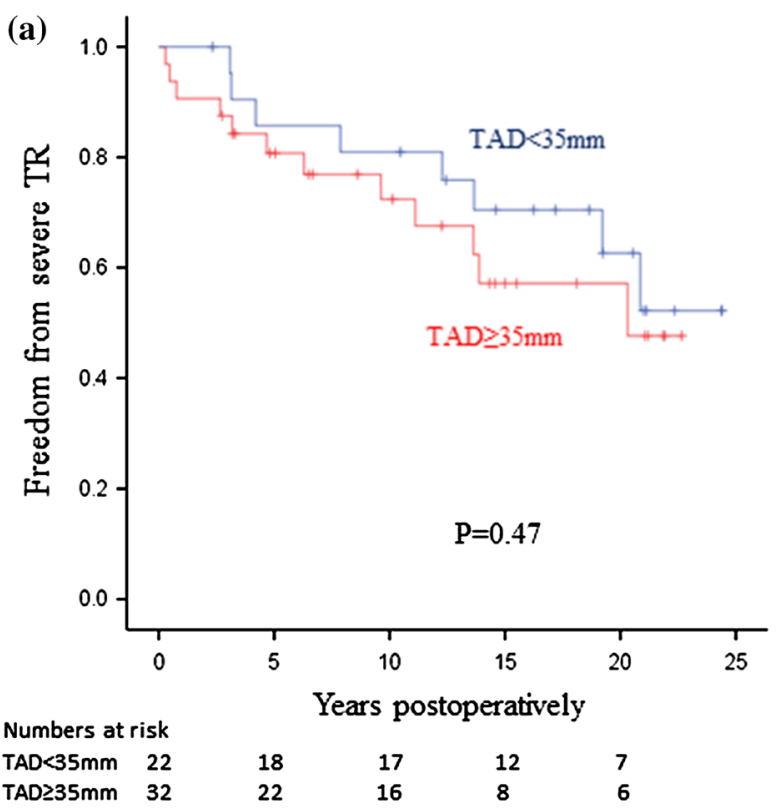

Fig. 7 Freedom from severe TR in the early-period patients according to the tricuspid annular diameter. The log-rank test did not show a significant difference between 32 patients with a TAD of $\geq 35 \mathrm{~mm}$ and 22 patients with a TAD of $<35 \mathrm{~mm}$ (a). Furthermore, there was

Some authors have hypothesized that tricuspid annular dilatation may be an ongoing disease process that continues even after the mitral valve lesion has been repaired

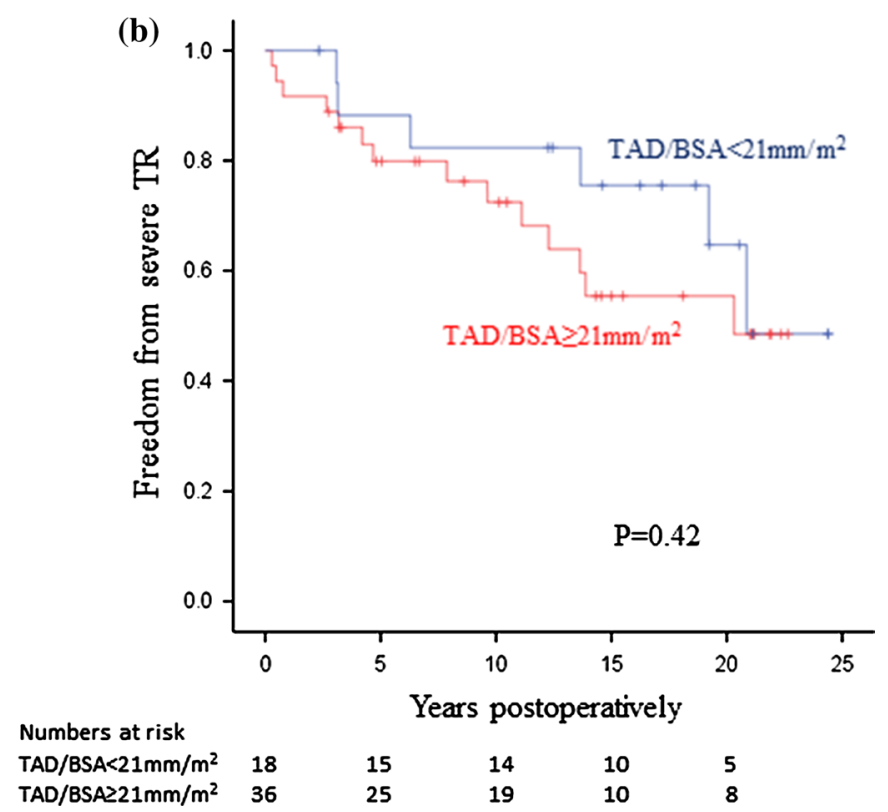

no difference between 36 patients with an indexed TAD of $\geq 21 \mathrm{~mm} /$ $\mathrm{m}^{2}$ and 18 patients with an indexed TAD of $<21 \mathrm{~mm} / \mathrm{m}^{2}(\mathbf{b})$. TR tricuspid regurgitation, $B S A$ body surface area, $T A D$ tricuspid annular diameter

[6]. This hypothesis may explain the findings of previous studies, which noted that the incidence of postoperative TR was higher in patients with rheumatic mitral disease than 
in those with degenerative mitral disease [24]. Additionally, a long time from the onset of mitral valve disease to surgery is a predictor of late TR after mitral valve surgery [9]. However, the hypothesis that tricuspid annular dilatation is an ongoing process is speculative and should be the subject of further studies.

\section{Study limitations}

The present study is associated with several limitations. First, this study was a retrospective analysis with a small sample size. Although our policy of tricuspid valve surgery was consistent during the study period, many surgeons were involved over a relatively long study period. A prospective study with a large number of patients would help to determine the risk factors for postoperative TR, as well as the importance of tricuspid annular dilatation. Second, over half of the patients had rheumatic heart disease, and the mitral valve was replaced in almost all of the patients. Although we accounted for these factors (e.g., rheumatic disease, mitral valve repair, the acute onset of mitral valve disease) in the analysis, our results may not be applicable to patients who undergo mitral valve repair for degenerative disease. Third, the severity of TR was mainly determined by comparing the regurgitant jet area with the right atrial area, rather than by the recommendations of the American Society of Echocardiography [33]. This is because most of the patients in this study underwent surgery before the recommendation had been reported. Finally, we did not evaluate the tethering of the tricuspid valve leaflets, the dimensions and functions of the right ventricle and atrium, or the shape of the tricuspid annulus. These details of the tricuspid valve complex should be further evaluated because they may help to predict secondary TR after mitral valve surgery.

\section{Conclusions}

Relatively high rates of patients without severe preoperative TR develop severe postoperative TR if the tricuspid valve is left untouched at the time of mitral valve surgery. Moderate preoperative TR is the most significant risk factor for severe postoperative TR. The aggressive application of TVR using a prosthetic ring may prevent the development of severe postoperative TR. The measurement of tricuspid annular dilatation by preoperative echocardiography might not be a good indicator of whether patients undergoing mitral valve surgery should undergo concomitant TVR. However, further study will be needed to confirm our results.

\section{Compliance with ethical standards}

Conflict of interest The authors declare no conflicts of interest in association with the present study.

Open Access This article is distributed under the terms of the Creative Commons Attribution 4.0 International License (http://creativecommons.org/licenses/by/4.0/), which permits unrestricted use, distribution, and reproduction in any medium, provided you give appropriate credit to the original author(s) and the source, provide a link to the Creative Commons license, and indicate if changes were made.

\section{References}

1. Groves PH, Lewis NP, Ikram S, Maire R, Hall RJ. Reduced exercise capacity in patients with tricuspid regurgitation after successful mitral valve replacement for rheumatic mitral valve disease. Br Heart J. 1991;66:295-301.

2. Nath J, Foster E, Heidenreich PA. Impact of tricuspid regurgitation on long-term survival. J Am Coll Cardiol. 2004;43:405-9.

3. Porter A, Shapira Y, Wurzel M, Sulkes J, Vaturi M, Adler Y, et al. Tricuspid regurgitation late after mitral valve replacement: clinical and echocardiographic evaluation. J Heart Valve Dis. 1999;8:57-62.

4. King RM, Schaff HV, Danielson GK, Gersh BJ, Orszulak TA, Piehler JM, et al. Surgery for tricuspid regurgitation late after mitral valve replacement. Circulation. 1984;70:I193-7.

5. Izumi C, Iga K, Konishi T. Progression of isolated tricuspid regurgitation late after mitral valve surgery for rheumatic mitral valve disease. J Heart Valve Dis. 2002;11:353-6.

6. Dreyfus GD, Corbi PJ, Chan KM, Bahrami T. Secondary tricuspid regurgitation or dilatation: which should be the criteria for surgical repair? Ann Thorac Surg. 2005;79:127-32.

7. Matsunaga A, Duran CM. Progression of tricuspid regurgitation after repaired functional ischemic mitral regurgitation. Circulation. 2005;112:I453-7.

8. Matsuyama K, Matsumoto M, Sugita T, Nishizawa J, Tokuda Y, Matsuo T. Predictors of residual tricuspid regurgitation after mitral valve surgery. Ann Thorac Surg. 2003;75:1826-8.

9. Wang G, Sun Z, Xia J, Deng Y, Chen J, Su G, et al. Predictors of secondary tricuspid regurgitation after left-sided valve replacement. Surg Today. 2008;38:778-83.

10. Anyanwu AC, Chikwe J, Adams DH. Tricuspid valve repair for treatment and prevention of secondary tricuspid regurgitation in patients undergoing mitral valve surgery. Curr Cardiol Rep. 2008;10:110-7.

11. Vahanian A, Alfieri O, Andreotti F, Antunes MJ, BaronEsquivias $\mathrm{G}$, Baumgartner $\mathrm{H}$, et al. Guidelines on the management of valvular heart disease (version 2012): the Joint Task Force on the Management of Valvular Heart Disease of the European Society of Cardiology (ESC) and the European Association for Cardio-Thoracic Surgery (EACTS). Eur J Cardio Thorac Surg Off J Eur Assoc Cardio Thorac Surg. 2012;42:S1-44.

12. Nishimura RA, Otto CM, Bonow RO, Carabello BA, Erwin JP 3rd, Guyton RA, et al. 2014 AHA/ACC guideline for the management of patients with valvular heart disease: executive summary: a report of the American College of Cardiology/American Heart Association Task Force on Practice Guidelines. J Am Coll Cardiol. 2014;63:2438-88. 
13. Chopra HK, Nanda NC, Fan P, Kapur KK, Goyal R, Daruwalla $\mathrm{D}$, et al. Can two-dimensional echocardiography and Doppler color flow mapping identify the need for tricuspid valve repair? J Am Coll Cardiol. 1989;14:1266-74.

14. Sagie A, Schwammenthal E, Padial LR, de Prada JAV, Weyman AE, Levine RA. Determinants of functional tricuspid regurgitation in incomplete tricuspid valve closure: Doppler color flow study of 109 patients. J Am Coll Cardiol. 1994;24:446-53.

15. Foale R, Nihoyannopoulos P, McKenna W, Kleinebenne A, Nadazdin A, Rowland E, et al. Echocardiographic measurement of the normal adult right ventricle. Br Heart J. 1986;56:33-44.

16. Izumi $\mathrm{C}$, Miyake $\mathrm{M}$, Takahashi $\mathrm{S}$, Matsutani $\mathrm{H}$, Hashiwada $\mathrm{S}$, Kuwano K, et al. Progression of isolated tricuspid regurgitation late after left-sided valve surgery. Clinical features and mechanisms. Circ J. 2011;75:2902-7.

17. Goldstone AB, Howard JL, Cohen JE, MacArthur JW Jr, Atluri P, Kirkpatrick JN, et al. Natural history of coexistent tricuspid regurgitation in patients with degenerative mitral valve disease: implications for future guidelines. J Thorac Cardiovasc Surg. 2014;148:2802-9.

18. Carpentier A, Deloche A, Hanania G, Forman J, Sellier P, Piwnica A, et al. Surgical management of acquired tricuspid valve disease. J Thorac Cardiovasc Surg. 1974;67:53-65.

19. Goldman ME, Guarino T, Fuster V, Mindich B. The necessity for tricuspid valve repair can be determined intraoperatively by two-dimensional echocardiography. J Thorac Cardiovasc Surg. 1987;94:542-50.

20. Tager R, Skudicky D, Mueller U, Essop R, Hammond G, Sareli P. Long-term follow-up of rheumatic patients undergoing leftsided valve replacement with tricuspid annuloplasty-validity of preoperative echocardiographic criteria in the decision to perform tricuspid annuloplasty. Am J Cardiol. 1998;81:1013-6.

21. Colombo T, Russo C, Ciliberto GR, Lanfranconi M, Bruschi G, Agati S, et al. Tricuspid regurgitation secondary to mitral valve disease: tricuspid annulus function as guide to tricuspid valve repair. Cardiovasc Surg. 2001;9:369-77.

22. Van de Veire NR, Braun J, Delgado V, Versteegh MI, Dion RA, Klautz RJ, et al. Tricuspid annuloplasty prevents right ventricular dilatation and progression of tricuspid regurgitation in patients with tricuspid annular dilatation undergoing mitral valve repair. J Thorac Cardiovasc Surg. 2011;141:1431-9.
23. Calafiore AM, Iaco AL, Romeo A, Scandura S, Meduri R, Varone E, et al. Echocardiographic-based treatment of functional tricuspid regurgitation. J Thorac Cardiovasc Surg. 2011;142:308-13.

24. Song H, Kim MJ, Chung CH, Choo SJ, Song MG, Song JM, et al. Factors associated with development of late significant tricuspid regurgitation after successful left-sided valve surgery. Heart. 2009;95:931-6.

25. Chan V, Burwash IG, Lam BK, Auyeung T, Tran A, Mesana TG, et al. Clinical and echocardiographic impact of functional tricuspid regurgitation repair at the time of mitral valve replacement. Ann Thorac Surg. 2009;88:1209-15.

26. Fisher EA, Goldman ME. Simple, rapid method for quantification of tricuspid regurgitation by two-dimensional echocardiography. Am J Cardiol. 1989;63:1375-8.

27. Groves PH, Ikram S, Ingold U, Hall RJ. Tricuspid regurgitation following mitral valve replacement: an echocardiographic study. J Heart Valve Dis. 1993;2:273-8.

28. Kim HK, Kim YJ, Park JS, Kim KH, Kim KB, Ahn H, et al. Determinants of the severity of functional tricuspid regurgitation. Am J Cardiol. 2006;98:236-42.

29. Tei C, Pilgrim JP, Shah PM, Ormiston JA, Wong M. The tricuspid valve annulus: study of size and motion in normal subjects and in patients with tricuspid regurgitation. Circulation. 1982;66:665-71.

30. Fukuda S, Song JM, Gillinov AM, McCarthy PM, Daimon M, Kongsaerepong V, et al. Tricuspid valve tethering predicts residual tricuspid regurgitation after tricuspid annuloplasty. Circulation. 2005;111:975-9.

31. Ton-Nu TT, Levine RA, Handschumacher MD, Dorer DJ, Yosefy C, Fan D, et al. Geometric determinants of functional tricuspid regurgitation: insights from 3-dimensional echocardiography. Circulation. 2006;114:143-9.

32. Misawa Y. Valve-related complications after mechanical heart valve implantation. Surg Today. 2015;45:1205-9.

33. Zoghbi WA, Enriquez-Sarano M, Foster E, Grayburn PA, Kraft $\mathrm{CD}$, Levine RA, et al. Recommendations for evaluation of the severity of native valvular regurgitation with two-dimensional and Doppler echocardiography. J Am Soc Echocardiogr. 2003;16:777-802. 